\title{
Trace metals and over-expression of metallothioneins in bladder tumoral lesions: a case-control study
} André FS Amaral*1,2,3, Teresa Cymbron ${ }^{2,4}$, Fátima Gärtner ${ }^{5}$, Manuela Lima ${ }^{2,4}$ and Armindo S Rodrigues 2,3

Address: ${ }^{1}$ Spanish National Cancer Research Centre (CNIO), Genetic and Molecular Epidemiology Group, Madrid, Spain, ${ }^{2} \mathrm{CIRN}, \mathrm{DB}, \mathrm{University}$ of the Azores, APT 1422, 9501-855 Ponta Delgada, Portugal, ${ }^{3}$ PHERG, University of the Azores, APT 1422, 9501-855 Ponta Delgada, Portugal, ${ }^{4}$ IBMC-Institute for Molecular and Cell Biology, University of Porto, 4150-180 Porto, Portugal and 5IPATIMUP, R. Dr. Roberto Frias, s/n, University of Porto, 4200-456 Porto, Portugal

Email: André FS Amaral* - aamaral@cnio.es; Teresa Cymbron - tcymbron@uac.pt; Fátima Gärtner - fgartner@ipatimup.pt; Manuela Lima - mlima@uac.pt; Armindo S Rodrigues - rodrigues@uac.pt

* Corresponding author

Published: II November 2009

BMC Veterinary Research 2009, 5:40 doi:10.1186/1746-6/48-5-40
Received: 30 October 2009

Accepted: II November 2009

This article is available from: http://www.biomedcentral.com/l746-6/48/5/40

(C) 2009 Amaral et al; licensee BioMed Central Ltd.

This is an Open Access article distributed under the terms of the Creative Commons Attribution License (http://creativecommons.org/licenses/by/2.0), which permits unrestricted use, distribution, and reproduction in any medium, provided the original work is properly cited.

\section{Correction}

During the publication process of this work [1], we noted that the column for nickel in table 2 was not showing the concentration values in the proper units. This change has been made in the updated table (see table 2).

\section{References}

I. Amaral AFS, Cymbron T, Gartner F, Lima M, Rodrigues AS: Trace metals and over-expression of metallothioneins in bladder tumoral lesions: a case-control study. BMC Veterinary Research 2009, 5:24

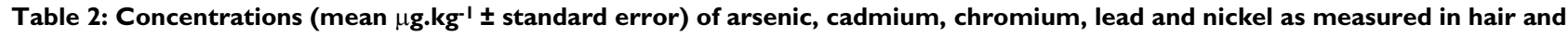
bladder tissue, from controls and case lesions.

\begin{tabular}{|c|c|c|c|c|c|}
\hline & Arsenic & Cadmium & Chromium & Lead & Nickel \\
\hline \multicolumn{6}{|l|}{ Bladder tissue } \\
\hline Controls $(n=17)$ & $19.94 \pm 6.46$ & $21.60 \pm 2.02$ & $269.41 \pm 38.18$ & $10.29 \pm 1.84$ & $80 \pm 30$ \\
\hline All cases $(n=37)$ & $23.00 \pm 2.62$ & $25.91 \pm 1.95$ & $247.84 \pm 33.36$ & $14.73 \pm 2.87$ & $70 \pm 10$ \\
\hline Carcinomas $(n=18)$ & $17.94 \pm 4.21$ & $20.83 \pm 2.13$ & $283.89 \pm 41.85$ & $13.33 \pm 3.77$ & $60 \pm 10$ \\
\hline \multicolumn{6}{|l|}{ Hair } \\
\hline Controls $(n=13)$ & $59.54 \pm 12.44$ & $16.25 \pm 3.01$ & $123.85 \pm 25.83$ & $460.77 \pm 176.78$ & $90 \pm 20$ \\
\hline All cases $(n=23)$ & $61.96 \pm 8.25$ & $23.20 \pm 2.39 a$ & $634.35 \pm 127.78^{a}$ & $1095.22 \pm 214.77^{a}$ & $300 \pm 50^{a}$ \\
\hline Carcinomas $(n=10)$ & $58.30 \pm 12.69$ & $21.61 \pm 3.44$ & $559.00 \pm 198.40^{a}$ & $960.00 \pm 318.04$ & $280 \pm 80^{a}$ \\
\hline
\end{tabular}

a differs significantly $(p \leq 0.05)$ from controls. 